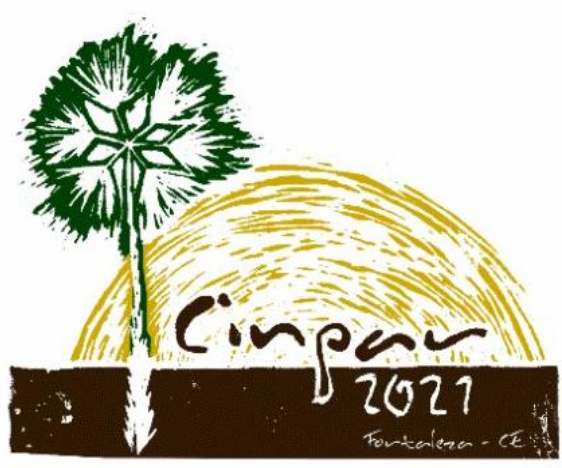

XVII Congresso Internacional sobre Patologia e

Reabilitação das Construções

XVII Congreso Internacional sobre Patología y Rehabilitación de las Construcciones

XVII International Conference on Pathology and Constructions Rehabilitation

FORTALEZA (Brasil), 3 a 5 de junho de 2021

https://doi.org/10.4322/CINPAR.2021.154

\title{
Caracterização de perfis de umidade ascensional em revestimentos argamassados tradicionais
}

\section{Characterization of the rising moisture profiles in traditional mortar coatings}

Francisco Lucas de Oliveira Freire', Luis Marcelo Gomes de Oliveira ${ }^{2}$, Esequiel Fernandes Teixeira Mesquita ${ }^{3}$

'LAREB, Universidade Federal do Ceará, Russas, Brasil, lucasolliveira93@alu.ufc.br ${ }^{2}$ PEC/LAREB, Universidade Federal do Ceará, Fortaleza, Brasil, Imarcelo05@alu.ufc.br ${ }^{3}$ LAREB, Universidade Federal do Ceará, Russas, Brasil, emesquita@ufc.br

Resumo: Medidas de preservação do patrimônio histórico e manutenção das alvenarias tradicionais tornam necessária a análise da estrutura em diferentes aspectos, como geometria, características construtivas e propriedades dos materiais. Essas informações são essenciais na avaliação do estado de conservação dessas construções, deteç̧ão de problemas e definição da estratégia de intervenção. Um dos principais promotores da degradação nas estruturas de alvenarias tradicionais é a presença de água. A água pode penetrar, dentre outras formas, por meio de ascensão capilar a partir do solo ou superfícies úmidas, fenômeno mais conhecido como umidade ascensional e que pode comprometer desde a estética até a capacidade resistiva das estruturas. Nesse trabalho, foi utilizado o software WUFI-2D para se realizarem simulações numéricas para avaliar o comportamento higrotérmico de revestimentos argamassados de alvenarias tradicionais, tendo como referência construções históricas do estado do Ceará. Os resultados mostraram que os materiais dos revestimentos e alvenaria devem ser compatíveis quanto a permeabilidade de vapor dos materiais. A incompatibilidade de materiais torna o revestimento uma barreira impermeável que pode contribuir para uma ascensão de frente úmida de até $0,25 \mathrm{~m}$, considerando as condições climáticas do ambiente.

Palavras-chave: Umidade ascensional. Simulação numérica. Revestimentos argamassados. Alvenarias tradicionais.

Abstract: Measures to preserve the historic heritage and maintain traditional masonry make it necessary to analyze the structure in different aspects, such as geometry, construction characteristics and material properties. This information is essential in assessing the state of conservation of these buildings, detecting problems and defining the intervention strategy. One of the main promoters of degradation in traditional masonry structures is the presence of water. Water can penetrate, among other ways, by means of capillary rise from the ground or moist surfaces, a phenomenon better known as ascending humidity and which can compromise from aesthetics to the resistive capacity of structures. In this work, the WUFI-2D software was used to perform numerical simulations to evaluate the hygrothermal behavior of traditional masonry masonry coatings, having as reference historical buildings in the state of Ceará. The results showed that the materials of the coatings and masonry must be compatible regarding the vapor permeability of the materials. The incompatibility of materials makes the coating an impermeable barrier that can contribute to a wet rise of up to $0.25 \mathrm{~m}$, considering the climatic conditions of the environment.

Keywords: Ascension humidity. Numerical simulation. Mortar coatings. Traditional masonry. 


\section{Introdução}

A preservação do patrimônio e das construções históricas $(\mathrm{CH})$ está condicionada à análise profunda da estrutura em diferentes aspectos, como geometria, características construtivas e propriedades dos materiais (BOSCATO et al., 2016) ' Conhecer o estado de conservação dessas construções permite identificar os danos existentes, bem como a estratégia de intervenção mais adequada, uma vez que essas edificações podem apresentar heterogeneidade nos métodos construtivos, características estruturais e materiais utilizados (BRANDÃO et al., 2018; HANSEN et al., 2017; NETO; MARTINI; MESQUITA, 2017), complexidade geométrica, ausência de informações acerca dos materiais utilizados e do comportamento dos elementos que as constituem (ALMEIDA, 2013; SANTOS et al., 2016).

Assim como os demais tipos de estruturas, as $\mathrm{CH}$ estão sujeitas a variados quadros de degradação, podendo essas variações serem causadas por ações antrópicas (alterações na edificação e no ambiente externo), eventos naturais (variações térmicas e ataques químicos) e ações dinâmicas, como vento e sismos (BRANDÃO et al., 2018). Muitas vezes, o surgimento de danos pode ser associado, também, à destruição progressiva dos materiais ao longo do tempo e à ausência de obras de renovação ou sua execução inadequada.

No caso das estruturas de alvenarias tradicionais, dentre as principais ocorrências de danos estão deslocamentos na fundação, degradação do material, deformações e, sobretudo, fissuração (NETO; MARTINI; MESQUITA, 2017; RAMOS et al., 2007). Segundo Kucera (KUCERA et al., 2017) o excesso de água na estrutura e nos materiais do edifício é a causa básica de problemas como a biodeterioração e a decomposição, afetando diretamente o conforto do usuário e a segurança e durabilidade da construção (CHANG; KIM, 2015; KOCl; KORECKY; CERNY, 2017; MAGALHÃES, 2018; RYMARCZYK et al., 2016; SLUSAREK; KRAUSE; SZYMANOWSKA-GWIZDZ, 2019).Nas alvenarias, a umidade excessiva pode causar fissuração por ação do congelamento-descongelamento, lixiviação de argamassa e corrosão de metal embutido (GUTLAND; BUCKING; QUINTERO, 2020), aém de danos aos revestimentos e ornamentos da arquitetura (HOLA et al., 2012). Dessa forma, seu controle é essencial para reduzir o risco de surgimento de danos à estrutura (VANPACHTENBEKE et al., 2020).

Dentre as formas de manifestação da umidade nas edificações destaca-se a umidade ascensional, que resulta da ascensão capilar de água a partir de solo úmido ou superfície úmida através dos capilares dos sólidos, podendo ocorrer tanto horizontalmente como verticalmente por áreas em contato com a água (MAGALHÃES, 2018). Este processo físico pode provocar diversos danos que comprometem desde a estética até a capacidade resistiva das estruturas (SILVA, 2013). Segundo (PAZDERKA; HÁJKOVÁ; JIRÁNEK, 2017), nas CH esse fenômeno é atribuído à ausência ou inadequada impermeabilização da subestrutura, caracterizada por manchas na superfície das paredes ou até desintegração da camada superficial.

Na umidade ascensional, a altura atingida pela ascensão capilar dependerá das condições climáticas do ambiente, da insolação, da presença de sais e das características dos materiais que constituem o objeto (TEIXEIRA, 2007). A progressão da frente úmida ocorre alcançar um equilíbrio entre a água que entra na parede por ascensão capilar e a água que sai por evaporação (FREITAS; TORRES; GUIMARÃES, 2008).

Embora tenham surgido modelos matemáticos e numéricos bidimensionais que simulam o comportamento higrotérmico das edificações, o fenômeno da umidade ascensional, muitas vezes, trata-se de um problema tridimensional, dependente da geometria da parede e suas interfaces (FREITAS; TORRES; GUIMARÃES, 2008). No entanto, modelos higrotérmicos são úteis na compreensão dos riscos de umidade e para o retrofit das estruturas (GRINT; MARINCIONI; ELWELL, 2020). Todavia, os resultados podem variar significativamente devido aspectos que podem ser fontes de incerteza na modelagem, como a inserção das informações relacionadas com as propriedades do material, as condições climáticas e a qualidade da construção, como juntas abertas e contato imperfeito entre os materiais (GUTLAND; BUCKING; QUINTERO, 2020). Embora existam obstáculos no tocante aos parâmetros de entrada que dificultem a representação da situação real, a modelagem higrotérmica apresenta resultados que podem nortear os profissionais na tomada de decisão, mas devem ser considerados de maneira cuidadosa (FREITAS; TORRES; GUIMARÃES, 2008).

Assim, o presente estudo tem como objetivo analisar o comportamento de diferentes tipos de revestimentos argamassados tradicionais de alvenarias de blocos cerâmicos maciços diante da umidade ascensional, tendo como referências as construções históricas e tradicionais do estado do Ceará, Brasil. Comparando-se os

Caracterização de perfis de umidade ascensional em revestimentos argamassados tradicionais 
diferentes materiais, bem como combinações entre eles, deseja-se determinar quais configurações apresentam melhores características que minimizam a umidade ascensional nessas construções.

\section{Metodologia}

O estudo foi realizado utilizando o software WUFI-2D, desenvolvido pelo Fraunhofer Institute for Building Physics (IBP), que é baseado no método dos volumes finitos e permite a modelagem de elementos de geometrias variadas. Embora possua limitações quanto às condições de fronteira das superfícies e interfaces de materiais, esta ferramenta é utilizada mundialmente por ser de fácil utilização por profissionais de engenharia e arquitetura (FREITAS; TORRES; GUIMARÃES, 2008).

Inicialmente, foi inserida a geometria em estudo: uma alvenaria histórica com $3 \mathrm{~m}$ de altura e espessura de $34 \mathrm{~cm}$, constituída de blocos maciços de $30 \mathrm{~cm}$ e revestida por uma argamassa de $2 \mathrm{~cm}$ em ambas as faces. Por ser uma representação 2D, a modelagem considerou a seção transversal da parede, destacando-se os revestimentos interno e externo e a alvenaria de blocos maciços. A partir da geometria, foi gerada uma malha numérica, em que foram feitos ajustes no número de elementos finitos para facilitar o processamento, composta por elementos retangulares, com 75 elementos na direção X e 75 elementos na direção Y.

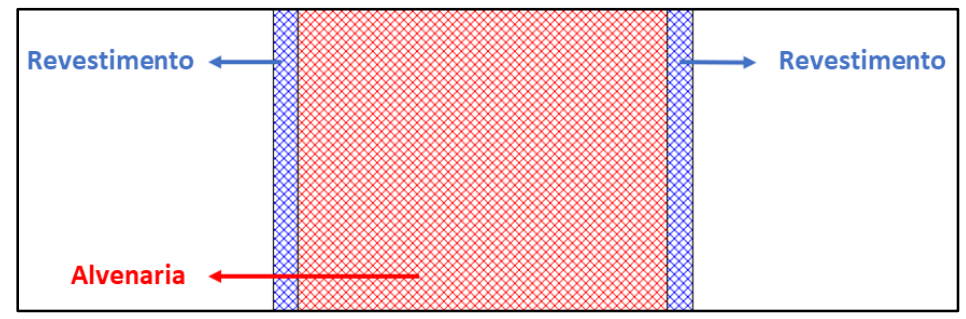

Figura 1 - Geometria do objeto estudado

Nesse estudo, foram utilizadas as propriedades dos materiais que constavam no banco de dados do software (Quadro 1), sendo cada teste realizado mantendo-se a alvenaria histórica de blocos maciços e alterando-se apenas os materiais dos revestimentos externos para se avaliar o efeito de cada combinação de materiais e determinar quais contribuem com a progressão da frente úmida e quais minimizam o efeito da umidade ascensional. Os revestimentos selecionados foram: argamassa histórica de cal e gesso (HCG); argamassa histórica de gesso (HG); argamassa de cimento, cal e gesso (CCG); e argamassa de cimento e gesso (CG).

Quadro 1 - Propriedades dos materiais utilizados

\begin{tabular}{|c|c|c|c|c|c|}
\hline Material & $\begin{array}{c}\text { Densidade } \\
\text { aparente } \\
\left(\mathrm{kg} / \mathrm{m}^{3}\right)\end{array}$ & $\begin{array}{c}\text { Porosidade } \\
\left(\mathrm{m}^{3} / \mathrm{m}^{3}\right)\end{array}$ & $\begin{array}{c}\text { Calor } \\
\text { específico } \\
(\mathrm{J} / \mathrm{kg} . \mathrm{K})\end{array}$ & $\begin{array}{c}\text { Condutibilidade } \\
\text { térmica }(\mathrm{seco}) \\
(\mathrm{W} / \mathrm{m} . \mathrm{K})\end{array}$ & $\begin{array}{c}\text { Fator de resistência à } \\
\text { difusão de vapor } \\
(\text { seco) }\end{array}$ \\
\hline HCG & 1571 & 0.39 & 850 & 0.82 & 9.61 \\
\hline HG & 915 & 0.64 & 850 & 0.52 & 7.80 \\
\hline CCG & 1900 & 0.24 & 850 & 0.80 & 19 \\
\hline CG & 2000 & 0.30 & 850 & 1.20 & 15 \\
\hline $\begin{array}{c}\text { Alvenaria de } \\
\text { bloco maciço }\end{array}$ & 1800 & 0.31 & 850 & 0.60 & 25 \\
\hline
\end{tabular}

Para a realização das simulações é necessária a entrada dos parâmetros climáticos da região de interesse. 0 software possui em seu banco de dados informações climáticas de algumas localidades, como os Estados Unidos da América e países da Europa. No entanto, quando não há informações para as regiões de interesse, os dados climáticos podem ser inseridos pelo usuário a partir dos valores da amplitude e média anual da temperatura e da umidade relativa locais. Para o presente estudo, foram utilizadas as temperaturas e umidades médias dos municípios de Sobral (S) e Fortaleza (F), ambos no estado do Ceará, disponibilizadas pelo Instituto Nacional de Meteorologia (INMET, 2020), considerando as normais relativas ao período de 1981 a 2010. O Quadro 2 apresenta as variáveis descritas, sendo calculada a média dos valores para cada 
mês no período em questão. As cidades de Sobra e Fortaleza foram selecionadas por possuírem um elevado número de construções históricas cearenses.

A partir do Quadro 2, obtiveram-se os parâmetros climáticos necessários: amplitude térmica de 2,5 (S) e 1,7 (F); temperatura média anual de 27,2 (S) e 26,9 (F); amplitude da umidade relativa de 29,7 (S) e 14,0 (F); umidade relativa média anual de 69,8 (S) e 77,5 (F). Esses valores foram utilizados para gerar as ondas senoidais que simulam o ambiente externo a qual a estrutura está submetida (Figura 2). Ademais, o software requer que especifique os dias em que a temperatura e a umidade relativa atingem os valores máximos. Assim, tanto para o município de Sobral como para Fortaleza, foram adotadas as datas 15 de dezembro e 15 de abril, para temperatura e umidade máximas, respectivamente, a partir da data intermediária dos meses com maiores médias do Quadro 2.

Quadro 2 - Normais Climatológicas de Sobral e Fortaleza no período 1981-2010

\begin{tabular}{|c|c|c|c|c|c|c|c|c|c|}
\hline \multicolumn{10}{|c|}{ NORMAIS CLIMATOLÓGICAS } \\
\hline \multirow[t]{2}{*}{ Mês } & \multicolumn{2}{|c|}{ Umidade relativa (\%) } & \multicolumn{2}{|c|}{$\begin{array}{c}\text { Temperatura média } \\
\text { compensada }\left({ }^{\circ} \mathrm{C}\right)\end{array}$} & \multirow[t]{2}{*}{ Mês } & \multicolumn{2}{|c|}{ Umidade relativa (\%) } & \multicolumn{2}{|c|}{$\begin{array}{c}\text { Temperatura média } \\
\text { compensada }\left({ }^{\circ} \mathrm{C}\right)\end{array}$} \\
\hline & Sobral & Fortaleza & Sobral & Fortaleza & & Sobral & Fortaleza & Sobral & Fortaleza \\
\hline Jan & 71.3 & 78.2 & 27.5 & 27.4 & Jul & 67.0 & 77.3 & 26.8 & 26.1 \\
\hline Fev & 79.0 & 79.6 & 26.7 & 27.4 & Ago & 59.3 & 73.4 & 27.5 & 26.4 \\
\hline Mar & 84.9 & 83.3 & 26.2 & 26.9 & Set & 56.8 & 71.1 & 28.1 & 26.9 \\
\hline $\mathrm{Abr}$ & 85.9 & 85.1 & 26.0 & 26.6 & Out & 56.2 & 71.5 & 28.3 & 27.3 \\
\hline Mai & 82.0 & 83.0 & 26.0 & 26.7 & Nov & 58.0 & 72.5 & 28.4 & 27.7 \\
\hline Jun & 73.9 & 80.6 & 26.1 & 26.1 & Dez & 63.7 & 74.2 & 28.5 & 27.8 \\
\hline \multicolumn{10}{|c|}{ Umidade relativa anual em Sobral (\%): 69.8} \\
\hline \multicolumn{10}{|c|}{ Temperatura média compensada em Sobral $\left({ }^{\circ} \mathrm{C}\right): 27.2$} \\
\hline \multicolumn{10}{|c|}{ Umidade relativa anual em Fortaleza (\%): 77.5} \\
\hline \multicolumn{10}{|c|}{ Temperatura média compensada em Fortaleza $\left({ }^{\circ} \mathrm{C}\right): 26.9$} \\
\hline
\end{tabular}

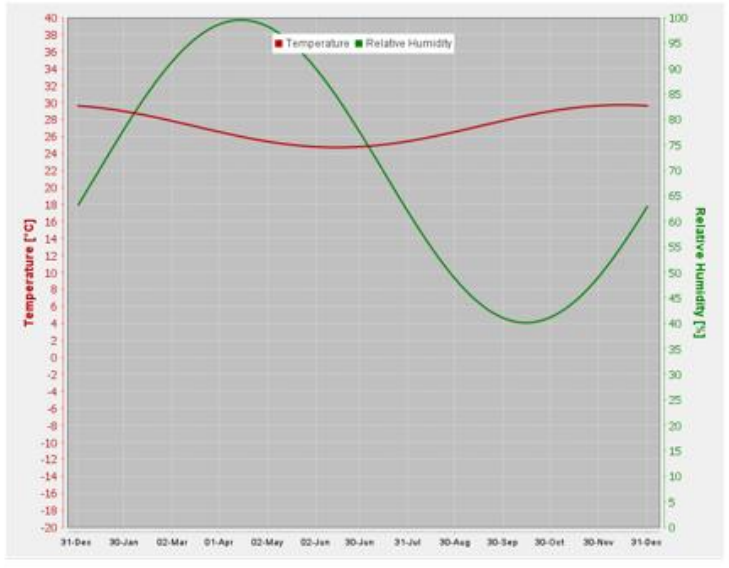

(a) Sobral, CE

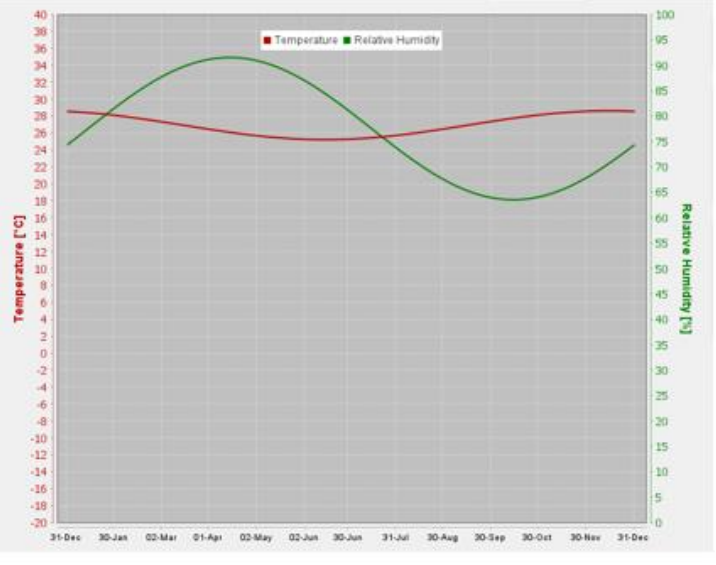

(b) Fortaleza, CE

Figura 2 - Ondas senoidais para a temperatura e a umidade

Na superfície em contato com o solo, foi considerada umidade relativa constante de $100 \%$, simulando contato total com a água, adaptado de (SILVA, 2013). Para as demais superfícies, foram adotados os valores de amplitude e média anual da umidade relativa dos municípios conforme descrito. Não foram especificadas condições climáticas para as superfícies de contato entre a alvenaria e os revestimentos, considerando-se os diferentes materiais como perfeitamente aderidos. Além disso, foram utilizadas as condições iniciais padrão do software, a saber: temperatura de $20^{\circ} \mathrm{C}$, teor de água de $4,5 \mathrm{~kg} / \mathrm{m}^{3}$ e umidade relativa de 0,8 . Em todas as configurações analisadas, os demais parâmetros e condições climáticas foram mantidos constantes, considerando-se o período de interesse do estudo, que foi de 1 ano, equivalente a 8760 horas. 
Inicialmente, considerou-se que as camadas de revestimento eram constituídas do mesmo material. Posteriormente, foram realizadas combinações entre os diferentes tipos de revestimentos para avaliar a influência de suas propriedades no fenômeno da umidade ascensional e a partir disso determinar quais configurações contribuem para a sua progressão e quais a minimizam.

\section{Resultados}

As simulações numéricas foram realizadas utilizando-se o mesmo material em ambos os revestimentos da parede de blocos maciços, referentes às configurações T1, T2, T3 e T4, com identificador $\mathrm{S}$ para o município de Sobral e F para o município de Fortaleza, e posteriormente combinando-se os demais materiais avaliados nos revestimentos da alvenaria, com resultados descritos na Figura 3 e no Quadro 3.

As simulações das diferentes argamassas nos revestimentos das alvenarias foram realizadas com o intuito de comparar os resultados e determinar aquela em que o fenômeno da umidade ascensional é minimizado, comparando-se cada material isoladamente e combinando com os demais. Além disso, a consideração de municípios distintos foi realizada para avaliar o efeito das condições climáticas no teor de umidade no interior das alvenarias.
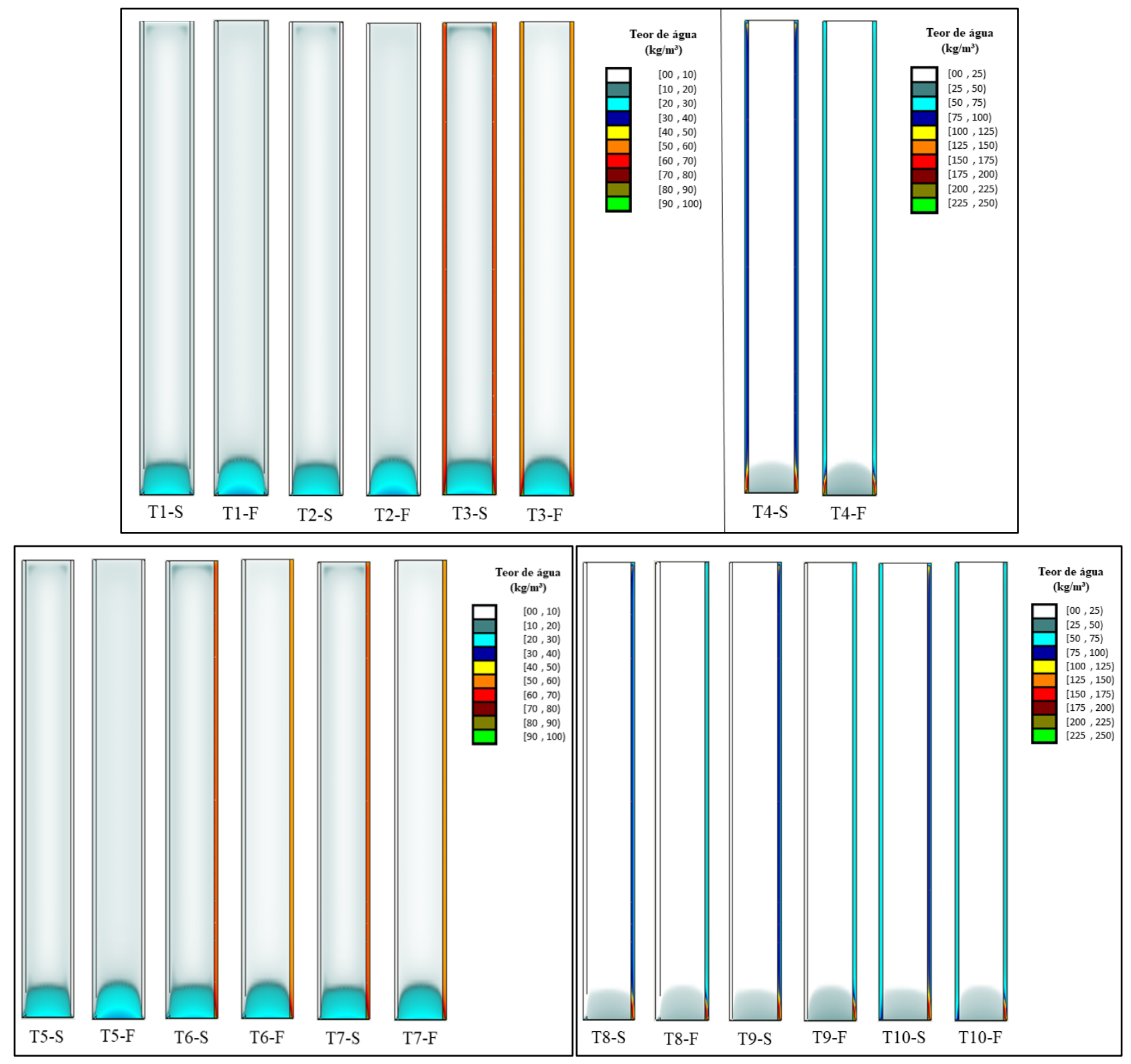

Figura 3 - Diagramas para materiais iguais em ambos revestimentos 
Quadro 3 - Altura da frente úmida

\begin{tabular}{|c|c|c|c|c|c|c|c|c|c|}
\hline \multirow{2}{*}{ Teste } & \multirow{2}{*}{ Material } & \multicolumn{3}{|c|}{ Altura } & \multirow{2}{*}{ Teste } & \multirow{2}{*}{ Material } & \multicolumn{3}{|c|}{ Altura } \\
\hline & & $S$ & $\mathbf{F}$ & Diferença & & & $S$ & $\mathbf{F}$ & Diferença \\
\hline Teste 1 & HCG - HCG & 0,21 & 0,25 & 0,04 & Teste 6 & HCG - CCG & 0,22 & 0,24 & 0,02 \\
\hline Teste 2 & HG - HG & 0,2 & 0,24 & 0,04 & Teste 7 & HG - CCG & 0,23 & 0,24 & 0,01 \\
\hline Teste 3 & CCG - CCG & 0,23 & 0,25 & 0,04 & Teste 8 & HCG - CG & 0,21 & 0,22 & 0,01 \\
\hline Teste 4 & CG - CG & 0,21 & 0,21 & 0 & Teste 9 & HG - CG & 0,2 & 0,23 & 0,03 \\
\hline Teste 5 & HCG - HG & 0,22 & 0,25 & 0,03 & Teste 10 & CCG - CG & 0,21 & 0,23 & 0,02 \\
\hline
\end{tabular}

Uma análise geral da altura máxima da frente úmida em cada uma das configurações evidencia um aumento na altura máxima atingida no interior dos materiais, considerando-se as condições climáticas de Fortaleza em relação à Sobral, sendo os acréscimos mínimo e máximo de $0,00 \mathrm{~m}$ e $0,04 \mathrm{~m}$, respectivamente. Considerando os parâmetros climáticos estabelecidos, o município de Fortaleza apresenta uma umidade relativa média anual maior comparada com o município de Sobral $\left(77,5^{\circ} \mathrm{C}\right.$ e $69,8^{\circ} \mathrm{C}$, respectivamente). Em decorrência disso, a maior umidade de Fortaleza contribuiu com um maior teor de umidade no interior das alvenarias, de forma a dificultar a evaporação da água nos capilares. Além disso, a temperatura média anual é maior em Sobral no período considerado no estudo $\left(27,2^{\circ} \mathrm{C}\right.$ contra $28,9^{\circ} \mathrm{C}$ de Fortaleza).

Analisando-se os teores de água no interior da alvenaria, as configurações que apresentaram uma maior umidade tinham em comum a utilização dos materiais CG e CCG em pelo menos um dos revestimentos. Pela Quadro 1, esses materiais apresentam um fator de resistência à difusão de vapor mais elevados, de forma que a umidade que penetra na parede por ascensão capilar tende a ficar contida no interior da estrutura devido a maior resistência a trocas de vapor com o ambiente externo estarem reduzidas. Como a ascensão capilar é interrompida quando é atingido um equilíbrio entre a evaporação e a água que entre por capilaridade, a maior resistência à ocorrência dessas trocas de umidade reduz a perda de umidade na parede, de forma que esta umidade se acumula na alvenaria sendo distribuída na geometria e contribuindo para uma maior frente úmida.

Segundo Vanpachtenbeke (2020), a permeabilidade a vapor deve ser crescente do interior para o exterior da parede para garantir o fluxo de umidade de dentro para fora. A resistência à difusão de vapor é a razão entre a permeabilidade do vapor de água do ar e a permeabilidade ao vapor de água do material poroso. Partindo desse ponto, para as paredes com revestimento CCG e CG, observa-se que o fator de resistência à difusão de vapor é crescente do interior para o exterior. Dessa forma, a permeabilidade ao vapor de água nos materiais é decrescente do interior para o exterior, assim, caracterizando um menor fluxo de umidade de dentro para fora na parede nas paredes com estas configurações.

Conforme apresentado por Faria (2008), as argamassas de edificações históricas devem apresentar boa compatibilidade mecânica, física e química com as alvenarias e simultaneamente suas características devem ser suficientes para suportar sua própria degradação. No entanto, com base nos testes realizados, as argamassas de CG e CCG se mostraram incompatíveis com as características da alvenaria em estudo, de forma que, assim como exposto por Kosa (2020), essa incompatibilidade acelerou o acúmulo de umidade no interior da parede. Essa incompatibilidade se deve à diferença no comportamento higroscópico dos materiais, pois a água que entra na edificação por capilaridade é confinada na alvenaria devido uma barreira impermeável criada pelos revestimentos argamassados de fator de resistência à difusão de vapor elevados.

Nas condições climáticas de Sobral, as configurações 3-S e 7-S apresentaram os maiores valores de frente úmida $(0,23 \mathrm{~m})$, enquanto para Fortaleza, os maiores valores foram obtidos para as configurações 1-F, 3-F e $5-\mathrm{F}(0,24 \mathrm{~m}$ nos três testes). Considerando-se as simulações realizadas para os dois municípios, a configuração das paredes com revestimento CCG em ambas as faces apresentou os maiores resultados de ascensão capilar, com valor altura da frente úmida de 0,23m para Sobral e 0,25 para Fortaleza. Pela Quadro 1, esse material possui menor porosidade, sendo, portanto, menos permeável que os demais tipos de revestimento estudados. Nessas condições, a diferença de permeabilidade entre os materiais constituintes do sistema produz um confinamento da umidade que ascende do solo, que se acumula no interior da peça. 
As configurações que apresentaram menor frente úmida eram compostas pelos materiais $\mathrm{HG}$ e CG, sendo os sistemas 2-S e 9-S para Sobral $(0,20 \mathrm{~m}$, ambos) e 4-F para Fortaleza $(0,21 \mathrm{~m})$. No entanto, desses materiais apenas o HG reduziu tanto a altura máxima do perfil de umidade quanto o teor de umidade no interior da parede em virtude da maior porosidade e menor fator de resistência à difusão de vapor, que possibilitaram uma troca de umidade mais eficiente entre a alvenaria e o ambiente externo, reduzindo a umidade interior, mais perceptível em Sobral. Para Fortaleza, embora o uso de HG não tenha refletido diretamente em um perfil de umidade ascensional menor, sua utilização provocou uma redução nos teores de umidade no interior da peça em relação aos demais materiais.

\section{Conclusão}

A presença de umidade no interior das edificações acelera seu processo de degradação impactando diretamente sua vida útil, sobretudo em construções e patrimônios históricos, e o conhecimento de como se dá a transferência de umidade entre o edificado e o ambiente é essencial para a realização de uma intervenção.

Comparando-se os dois municípios analisados, as diferenças nas condições climáticas impactaram diretamente nos perfis de umidade ascensional nas alvenarias, com resultados mais acentuados em regiões de maior umidade relativa do ar, o que se verificou por meio da comparação dos resultados obtidos para Sobral e Fortaleza. Além disso, as propriedades de diferentes materiais provocaram cenários diferentes quanto à umidade ascensional: a argamassa de cimento, cal e gesso resultou em uma maior frente úmida devido sua menor porosidade e maior resistência à difusão de vapor, para as duas regiões analisadas; a argamassa histórica de gesso minimizou o efeito da ascensão capilar devido sua maior porosidade e menor resistência à difusão de vapor, sobretudo nas condições climáticas de Sobral (para Fortaleza, sua influência foi mais perceptível quanto a menor distribuição de umidade no interior da alvenaria). Além disso, as configurações que utilizaram esses materiais apresentaram um efeito favorável para a ascensão capilar (para o primeiro material) e desfavorável ao fenômeno (para o segundo material), seja na redução da altura máxima da frente úmida, seja no teor de umidade no interior da alvenaria.

É importante destacar que, com base nas simulações realizadas, o fator de resistência à difusão de vapor teve grande influência na umidade total da parede, visto que um valor menor desse parâmetro ocasiona uma circulação de água maior no interior da parede provinda do solo pela ascensão capilar, favorecendo a saída de umidade da alvenaria por meio da evaporação, bem como conduzirá as trocas de umidade entre o meio interno e o ambiente externo.

Por fim, as diferentes combinações analisadas destacaram a importância de se conhecer previamente os materiais existentes em um edificado e aqueles que serão usados em uma possível intervenção, e como eles interagem, de forma a antever um possível agravamento dos problemas existentes, por exemplo, devido uma diferença de permeabilidade, conforme verificado no estudo.

\section{Referências bibliográficas}

ALMEIDA, C. M. N. V. DE. Paredes de alvenaria do Porto: Tipificação e Caraterização experimental. Porto, Portugal: Faculdade de Engenharia da Universidade do Porto, 2013.

BOSCATO, G. et al. Optimized procedures and strategies for the dynamic monitoring of historical structures. Journal of Civil Structural Health Monitoring, v. 6, n. 2, p. 265-289, abr. 2016.

BRANDÃO, F. et al. Dynamic characterization of a heritage construction from 19th century. Revista IBRACON de Estruturas e Materiais, v. 11, n. 1, p. 52-75, fev. 2018.

CHANG, S. J.; KIM, S. Hygrothermal performance of exterior wall structures using a heat, air and moisture modeling. Energy Procedia. Anais...Torino, Italy: 2015. Disponível em: <http://dx.doi.org/10.1016/j.egypro.2015.12.328>

FARIA, P.; HENRIQUES, F.; RATO, V. Comparative evaluation of lime mortars for architectural conservation. Journal of Cultural Heritage - J CULT HERIT, v. 9, p. 338-346, 1 jul. 2008. 
FREITAS, V. P. DE; TORRES, M. I.; GUIMARÃES, A. S. Humidade Ascensional. 1. ed. Porto: Faculdade de Engenharia da Universidade do Porto, 2008.

GRINT, N.; MARINCIONI, V.; ELWELL, C. A. Sensitivity and Uncertainty analyses on a DELPHIN model: The impact of material properties on moisture in a solid brick wall. E3S Web of Conferences. Anais...Tallinn, Estonia: 2020. Disponível em: <http://dx.doi.org/10.1051/e3sconf/202017204006>

GUTLAND, M.; BUCKING, S.; QUINTERO, M. S. Two-dimensional hygrothermal modelling of masonry walls accounting for imperfections at the masonry joint. E3S Web of Conferences. Anais...Tallinn, Estonia: 2020. Disponível em: <http://dx.doi.org/10.1051/e3sconf/202017208003>

HANSEN, T. et al. Material characterization models and test methods for historic building materials. Energy Procedia. Anais...Trondheim, Norway: 2017.2 Disponível em: <http://dx.doi.org/10.1016/j.egypro.2017.09.738>

HOLA, J. et al. Identification of moisture content in brick walls by means of impedance tomography. COMPEL: Int J for Computation and Maths. in Electrical and Electronic Eng., v. 31, 9 nov. 2012.

INMET, I. N. DE M. Normais Climatológicas do Brasil. Disponível em: <http://www.inmet.gov.br/portal/index.php?r=clima/normaisClimatologicas>. Acesso em: 24 jul. 2020.

KOCI, J.; KORECKY, T.; CERNY, R. Identification of Moisture Diffusivity of Autoclaved Aerated Concrete in the Form of Smooth Two-Variable Function. Energy Procedia. Anais...Trondheim, Norway: 2017. Disponível em: <http://dx.doi.org/10.1016/j.egypro.2017.09.758>

KOSA, Z.; TOROK, A. Characterization of historic binders and stones of a ruined medieval church (Hungary). Periodica Polytechnica Civil Engineering, v. 64, n. 2, p. 597-604, fev. 2020.

KUCERA, R. et al. Analysis and Design Rehabilitation Foundation of Timber Houses in Scandinavian Climate Condition. Procedia Engineering. Anais...Elsevier Ltd, 2017

MAGALHÃES, V. T. DE V. E A. DE. Humidade no Património. Porto: Faculdade de Engenharia da Universidade do Porto, 2018.

NETO, F. C.; MARTINI, R.; MESQUITA, E. F. T. Caracterização dos danos da estação ferroviária Doutor João Felipe. XII Congresso Internacional sobre Patologia e Reabiitação de Estruturas. Anais...Crato, Brasil: 2017.

PAZDERKA, J.; HÁJKOVÁ, E.; JIRÁNEK, M. Underground air duct to control rising moisture in historic buildings: Improved design and its drying efficiency. Acta Polytechnica, v. 57, n. 5, p. 331-339, 2017.

RAMOS, L. F. et al. Monitoring of historical masonry structures with operational modal analysis: Two case studies. Copenhage, Dinamarca: 2007

RYMARCZYK, T. et al. New electrical tomographic method to determine dampness in historical buildings. Archives of Electrical Engineering, v. 65, n. 2, p. 273-283, 2016.

SANTOS, F. et al. Análise estrutural de uma edificação histórica do século XVIII. Congresso Brasileiro de Patologia das Construções - CBPAT 2016. Anais...2016.

SILVA, N. S. DE A. E. Simulação numérica da influência da interface no fenómeno da humidade ascensional - Wufi 2D. Porto: Faculdade de Engenharia da Universidade do Porto, 2013.

SLUSAREK, J.; KRAUSE, P.; SZYMANOWSKA-GWIZDZ, A. Moistening of Walls Caused by Damage to Terraces Research Studies and Numerical Simulations. IOP Conference Series: Materials Science and Engineering, v. 471, n. 8, p. 0-9, 2019.

TEIXEIRA, A. S. M. DOS S. G. Caracterização experimental do funcionamento de sistemas de ventilação da base das paredes para tratamento da humidade ascensional. Porto: Faculdade de Engenharia da Universidade do Porto, 2007.

VANPACHTENBEKE, M. et al. Hygrothermal performance of timber frame walls with brick veneer cladding: A parameter analysis. E3S Web of Conferences. Anais...Tallinn, Estonia: 2020. Disponível em: <http://dx.doi.org/10.1051/e3sconf/202017207002> 